TITLE:

\title{
Glutathione peroxidase 2 in Saccharomyces cerevisiae is distributed in mitochondria and involved in sporulation
}

\section{AUTHOR(S):}

Ukai, Yuuta; Kishimoto, Tomoyuki; Ohdate, Takumi; Izawa, Singo; Inoue, Yoshiharu

\section{CITATION:}

Ukai, Yuuta ... [et al]. Glutathione peroxidase 2 in Saccharomyces cerevisiae is distributed in mitochondria and involved in sporulation. Biochemical and Biophysical Research Communications 2011, 411(3): 580-585

\section{ISSUE DATE:}

2011-08

URL:

http://hdl.handle.net/2433/145971

\section{RIGHT:}

C 2011 Elsevier Inc.; この論文は出版社版でありません。引用の際には 出版社版をご確認ご利用ください。; This is not the published version. Please cite only the published version. 
Running title: Localization of Gpx2 in yeast mitochondria

Glutathione Peroxidase 2 in Saccharomyces cerevisiae Is Distributed in Mitochondria and Involved in Sporulation

Yuuta Ukai, Tomoyuki Kishimoto, Takumi Ohdate ${ }^{1}$, Singo Izawa ${ }^{2}$, and Yoshiharu Inoue*

Laboratory of Molecular Microbiology, Division of Applied Life Sciences, Graduate School of Agriculture, Kyoto University, Uji, Kyoto 611-0011, Japan

${ }^{1}$ Present address: Department of Microbiology, Tohoku Pharmaceutical University, Sendai, Japan.

${ }^{2}$ Present address: Laboratory of Microbial Technology, Graduate School of Science and Technology, Kyoto Institute of Technology, Kyoto, Japan.

*Corresponding author. Tel. +81 774-38-3773. Fax. +81 774-38-3789. E-mail address: y_inoue@kais.kyoto-u.ac.jp (Y. Inoue). 


\begin{abstract}
Gpx2, one of three glutathione peroxidase homologues (Gpx1, Gpx2, and Gpx3) in Saccharomyces cerevisiae, is an atypical 2-Cys peroxiredoxin that prefers to use thioredoxin as

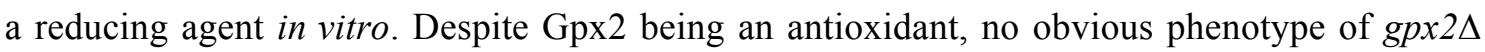
mutant cells in terms of oxidative stress has yet been found. To gain a clue as to Gpx2's physiological function in vivo, here we identify its intracellular distribution. Gpx2 was found to exist in the cytoplasm and mitochondria. In mitochondria, Gpx2 was associated with the outer membrane of the cytoplasmic-side, as well as the inner membrane of the matrix-side. The redox state of the mitochondrial Gpx2 was regulated by Trx 1 and Trx 2 (cytoplasmic thioredoxin), and by Trx3 (mitochondrial matrix thioredoxin). In addition, we found that the disruption of GPX2 reduced the sporulation efficiency of diploid cells.
\end{abstract}

Key words: glutathione peroxidase, Saccharomyces cerevisiae, peroxiredoxin, mitochondria, sporulation

\title{
1. Introduction
}

All organisms take up organic compounds from the environment, and derive electrons from such compounds to regenerate reductive coenzymes for energy production. In particular, aerobic organisms use molecular oxygen $\left(\mathrm{O}_{2}\right)$ as the final acceptor of electrons at the final step in the electron transfer system for ATP production. $\mathrm{O}_{2}$ accepts four electrons one by one, and consequently, several intermediates are generated. $\mathrm{O}_{2}$ per se is a biradical, but it is not as 
reactive as the intermediates generated during the reduction of $\mathrm{O}_{2}$, which in turn are referred to as reactive oxygen species. Hence, for all aerobic organisms, it is unavoidable that reactive oxygen species are generated during energy production. Organisms of all types are armed with several antioxidant systems. For example, one-electron-reduction of $\mathrm{O}_{2}$ yields superoxide anion radicals $\left(\mathrm{O}_{2}{ }^{-}\right)$, which are disproportionated to $\mathrm{O}_{2}$ and hydrogen peroxide $\left(\mathrm{H}_{2} \mathrm{O}_{2}\right)$ by superoxide dismutase. The $\mathrm{H}_{2} \mathrm{O}_{2}$ thus formed is decomposed to $\mathrm{O}_{2}$ and $\mathrm{H}_{2} \mathrm{O}$ by catalase, or reduced to $\mathrm{H}_{2} \mathrm{O}$ by peroxidases with different electron donors. Generally, peroxidases are named according to the electron donors that they use, e. $g$. ascorbate peroxidase, glutathione peroxidase, and thioredoxin peroxidase. We have previously reported that the budding yeast Saccharomyces cerevisiae has three glutathione peroxidase (GPx) homologues (Gpx1, Gpx2, and Gpx3) [1].

Peroxiredoxins (Prxs) are ubiquitous antioxidants in all types of organisms [2], which are characterized by certain common properties in that they do not contain a redox active cofactor or prosthetic group, and contain conserved Cys residue(s). According to the number of conserved Cys residues, Prxs are divided into two major groups, i.e. 1-Cys Prx and 2-Cys Prx. In both Prxs, the N-terminal Cys, which is sometimes referred to as the peroxidatic Cys, is conserved. In 2-Cys Prx, another Cys residue that is referred to as the resolving Cys is conserved, and two intermolecular disulfide bonds are formed between the peroxidatic Cys and resolving Cys as a consequence of the reduction of peroxides, and subsequently a Prx dimer is formed. Meanwhile, in a family of atypical 2-Cys Prxs, an intramolecular disulfide bond is formed within the same molecule. We have previously reported that Gpx1 and Gpx2 are atypical 2-Cys peroxiredoxins using both glutathione and thioredoxin as regucing agents $[3,4]$, while Delaunay et al. [5] have reported that Gpx3 shows thioredoxin peroxidase activity in 
vitro.

Since the expression of GPX3 is constitutive, and besides being an antioxidant, Gpx3 functions as a redox sensor and transducer of the oxidative stress-responsive transcription factor Yap1 [5], gpx3 3 mutant cells exhibit a clear phenotype in terms of the loss of the antioxidant [1]. Meanwhile, even though Gpx1 and Gpx2 show peroxidase activity in vitro [3,4], neither gpx $1 \Delta$ nor gpx $2 \Delta$ cells demonstrate any obvious phenotypes in terms of oxidative stress [1]. To gain a clue as to Gpx2's physiological function in vivo, we determined its intracellular localization. Here we show that Gpx2 is distributed in both the cytoplasm and mitochondria. We explored the roles of Gpx2 with respect to mitochondria, and found that Gpx2 is involved in the process of sporulation, i. e. the loss of Gpx2 decreased the sporulation efficiency of diploid cells.

\section{Materials and methods}

\subsection{Strains and media}

The $S$. cerevisiae strains used in this study are summarized in Supplemental Table1. Cells were grown in YPD medium ( $2 \%$ glucose, $1 \%$ yeast extract, and $2 \%$ peptone), or synthetic dextrose (SD) medium ( $2 \%$ glucose, $0.67 \%$ yeast nitrogen base without amino acid) with appropriate amino acids and bases at $28^{\circ} \mathrm{C}$. For peroxide treatment, $0.4 \mathrm{mM} \mathrm{H} \mathrm{H}_{2} \mathrm{O}_{2}$ was added to the culture, in which logarithmically growing cells are involved, and incubated for 60 $\min$

\subsection{Gene disruption}




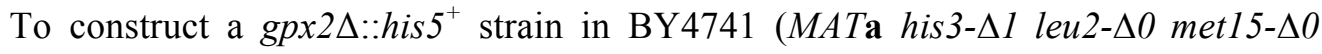
ura3- $\Delta 0$ ), pUG27 [6] was digested with BglII and SacI, and the resultant fragment containing his $5^{+}$was replaced with KanMX4 at the gpx2 $2:: K a n M X 4$ locus of BY4741 (Invitrogen). To construct a gpx $2 \Delta:: h i s 5^{+}$strain in YPH252, the allele of gpx $2 \Delta::$ his $5^{+}$in BY4741 was amplified by PCR with the following primers : GPX2-1, 5'-TTACCGTTGTCGACCTTGCTCTAC-3', and GPX2RA, 5'-TCAGAAGCAGGACACCTGTAGAGCTAGCCA-3'. The PCR fragment was introduced into YPH252. To construct $g p x 2 \Delta:: T R P 1$, pUGI4 [1] was digested with Tth111I followed by Klenow treatment, and the TRP1 gene was ligated (pUC19-gpx $2 \Delta:: T R P 1)$. The gpx $2 \Delta:: T R P 1$ fragment was amplified by PCR using the primers GPX2-FT (5'-TTAATGTTGCCTCCAAGTGC-3') and GPX2-RT (5'-TTGGTCCAAGGACGATGG-3') with pUC19-gpx2 $2::$ TRP1 as a template DNA. The PCR fragment was introduced into YPH250 to disrupt GPX2.

$\begin{array}{rrrrr}\text { FMP45 was amplified } & \text { by } & \text { PCR } & \text { with } & \text { Fmp45-F, } \\ \text { 5'-GAAAGAGGAATTCAGGTTTAACGCTT-3', } & \text { and } & & \text { Fmp45-R, }\end{array}$
5'-TTGGAGGTAGAAGCTTAGTTATGGTAC-3'. Fmp45-F and Fmp45-R are designed with EcoRI and HindIII sites, respectively (underlined). The resultant PCR fragment was cloned into the EcoRI-HindIII sites of pUC19 to yield pUC-FMP45. To disrupt the FMP45 gene, the following two plasmids were constructed: pUC-FMP45 was digested with Eco47III and HincII to delete a part of the open reading frame of FMP45, and URA3 or LEU2 was inserted to yield pUC19-fmp45 $\Delta:: U R A 3$ and pUC19-fmp45 $::$ URA3, respectively. To construct fmp $45 \Delta:: U R A 3$ and $f m p 45 \triangle:: L E U 2$ strains, PCR was performed with primers Fmp45-F and Fmp45-R using pUC19-fmp45 $::$ URA3 or pUC19-fmp45 $\Delta::$ LEU2 as a template, and the amplified fragment 
was introduced into YPH250 and YPH252, respectively.

\subsection{Western blotting}

After SDS-polyacrylamide gel electrophoresis (SDS-PAGE), separated proteins were transferred to a PVDF membrane (Immobilon, Millipore). To detect proteins of interest, antibodies for each protein [anti-Gpx2 [4], anti-Por1 (Cell Signaling), anti-Dpm1 (Cell Signaling), anti-Pgk1 (Cell Signaling), anti-Tom70 [7], anti-Tim50 [7], and anti-Hsp60 [7] antibodies] were used. Anti-rabbit IgG conjugated with alkaline phosphatase (Cell Signaling) was used as the secondary antibody, and the immunoreacted bands were visualized with a BCIP-NBT kit (Nacalai tesque).

\subsection{Subcellular fractionation}

The subcellular fractionation experiment, and sucrose density gradient ultracentrifugation was done essentially as described by Meisinger et al. [8]. Details as to the experimental conditions are described in the Supplemental Materials and methods.

\subsection{Determination of submitochondrial localization of Gpx2}

Treatment of mitochondria with proteinase $\mathrm{K}, \mathrm{NaCl}$, sonication, and $\mathrm{Na}_{2} \mathrm{CO}_{3}$ to determine the localization of proteins was done essentially as described by Yamamoto et al. [9]. Details as to the experimental conditions are described in the Supplemental Materials and methods. 


\subsection{Determination of the redox states of mitochondrial Gpx2}

The modification of Cys residues of Gpx2 was performed basically as described by Tanaka et al. [4]. The crude mitochondria (200 $\mu \mathrm{g}$ protein) in $200 \mu \mathrm{l}$ of SEM [ $250 \mathrm{mM}$ sucrose, $1 \mathrm{mM}$ EDTA, and $10 \mathrm{mM}$ MOPS (pH 7.2)] buffer were mixed with $50 \mu 1$ of $100 \%$ TCA, the mixture was centrifuged at $13000 \mathrm{xg}$ for $10 \mathrm{~min}$ at $4^{\circ} \mathrm{C}$, and the precipitates were washed once with acetone. After removal of the acetone, the dried materials were suspended with $40 \mu 1$ of sample buffer $[80 \mathrm{mM}$ Tris- $\mathrm{HCl}(\mathrm{pH}$ 6.8), 2\% SDS, $6 \mathrm{M}$ urea, $1 \mathrm{mM}$ PMSF, and $0.05 \%$ bromophenol blue] containing $20 \mathrm{mM}$ 4'-acetamido-4'-maleimidylstilbene-2, 2'-disulfonic acid

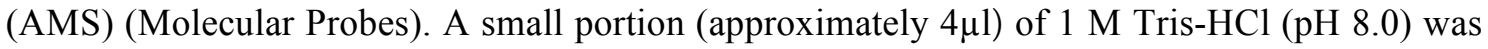
added to adjust the $\mathrm{pH}$ of the sample, and the mixture was boiled for 2 min. Twenty microliters of the sample was subjected to non-reducing SDS-PAGE followed by Western blotting using anti-Gpx2 antibody to determine the redox state of Gpx2 in mitochondria.

\subsection{Determination of sporulation efficiency}

Diploid cells grown for 1 day on YPD agar plates were suspended in a $0.85 \% \mathrm{NaCl}$ solution, and diluted with a $0.85 \% \mathrm{NaCl}$ solution to bring the $A_{610}$ to 0.1 . The cell suspension was spotted in quintuplicate $(5 \mu \mathrm{l}$ each) onto plates containing sporulation medium $(1 \%$ potassium acetate, $0.1 \%$ yeast extract, $0.05 \%$ glucose, $2 \%$ agar, and appropriate amino acids), and incubated at $25^{\circ} \mathrm{C}$. On each day of incubation, all the cells of one of five spots were recovered, and suspended in the $0.85 \% \mathrm{NaCl}$ solution. The numbers of sporulated cells forming spores were counted using a microscope. 


\section{Results}

\subsection{Gpx2 is distributed in both mitochondria and cytoplasm}

Though Gpx2 is an atypical 2-Cys Prx that prefers to use thioredoxin as a reducing agent in vitro [4], gpx2 $\Delta$ cells do not exhibit any obvious phenotype regarding peroxide sensitivity. To gain insights into its function in vivo, we tried to determine the subcellular localization of Gpx2. We found that Gpx2 was present in not only soluble fractions but also insoluble fractions, so it is feasible that Gpx2 exists in some organelles. To address this possibility, we fractionated cell homogenates by a subsequent centrifugation, and found that Gpx2 was predominantly located in the crude mitochondrial fractions (P13) and in the cytoplasmic fractions (S13) (Fig. 1A). In $\mathrm{H}_{2} \mathrm{O}_{2}$-treated cells, the overall $\mathrm{Gpx} 2$ level was increased as reported previously [1], and Gpx2 was detected in both the crude mitochondria and cytoplasm (Fig. 1A).

In the preparation of mitochondria by centrifugation, the ER contaminates the crude mitochondrial fractions. As shown in Fig. 1A, both Por1 (mitochondrial marker protein) and Dpm1 (ER marker protein) were detected in the crude mitochondrial fractions (P13). Therefore, to eliminate the ER, these samples were subjected to a three-step sucrose density gradient ultracentrifugation. As shown in Fig. 1B, the pattern of fractionation of Gpx2 coincided with that of Por1 but not Dpm1. Therefore, Gpx2 is likely to be located in both mitochondria and the cytoplasm in yeast cells.

\subsection{Submitochondrial localization of Gpx2}

Next, we determined the submitochondrial localization of Gpx2. Mitochondria were 
treated with proteinase $\mathrm{K}(\mathrm{PK})$. The principle of this experiment is as follows: in whole mitochondria, PK can digest only proteins associated with the surface of mitochondria; in mitoplasts, PK can also digest proteins in the intermembrane space and those associated with the surface of the inner membrane facing the intermembrane space; and in solubilized mitoplasts, PK can also digest proteins in the matrix. As shown in Fig. 2A, when whole mitochondria were treated with $\mathrm{PK}$, Tom70, an outer membrane-integrated protein, was digested completely, because a large part of Tom70 is exposed at the surface of the mitochondrial outer membrane. However, approximately half of the mitochondrial Gpx2 was not digested under the same conditions. These results imply that some Gpx2s seem to exist on the surface of the outer membrane of mitochondria, but the rest are likely to be sequestered in mitochondria where PK cannot reach. Next, when mitoplasts were treated with PK, Gpx2 still remains within the mitoplasts, which implies that Gpx2 exists neither in the intermembrane space nor on the surface of the inner membrane facing the intermembrane space. In the PK treatment of solubilized mitoplasts, the rest of the Gpx2s were digested, a pattern which resembles Hsp60, a matrix marker protein. Therefore, Gpx2 seems to exist in the matrix also.

\subsection{Gpx2 is associated with the surface of mitochondrial membranes via ionic interaction}

To further explore the mode of existence of Gpx2 in the submitochondrial compartment, we treated mitochondria with $\mathrm{NaCl}$, sonication, and $\mathrm{Na}_{2} \mathrm{CO}_{3}$. As shown in Fig. 2B, some Gpx2 was released from whole mitochondria to the supernatant fractions after treatment with $0.5 \mathrm{M} \mathrm{NaCl}$ for $60 \mathrm{~min}$. However, Tom70 was not released from whole mitochondria under the same conditions, because this protein is integrated in the outer mitochondrial 
membrane. This result indicates that Gpx2 is not a membrane-integrated protein, but associated with the outer membrane through the ionic interaction.

Sonication disrupts the mitochondrial membrane. After sonication, the disrupted mitochondria were centrifuged. As a result, Gpx2 was mainly detected in the precipitates (Fig. 2B). This behavior in terms of protein localization resembles that of Tom70 and Tim50, integrated in the outer and inner membrane of mitochondria, respectively; but is different from that of Hsp60, a soluble protein in the matrix. This result also indicates that Gpx2 is a membrane-associated protein.

$\mathrm{Na}_{2} \mathrm{CO}_{3}$ also destroys mitochondria. After centrifugation of the $\mathrm{NO}_{2} \mathrm{CO}_{3}$-treated mitochondria, Gpx2 was mainly detected in the supernatants. This behavior resembles that of Tam41 (data not shown), a peripheral membrane protein [10], but is different from that of Tom70 and Tim50, membrane-integrated proteins (Fig. 2B). This result indicates that Gpx2 is a peripheral membrane protein not a membrane-integrated protein. Taken together, Gpx2 is a peripheral protein positioned on the outer membrane of mitochondria facing the cytoplasm via ionic interaction, as well as on the inner membrane facing the matrix.

\subsection{Redox regulation of mitochondrial Gpx2}

Previously, we have shown that the redox state of the bulk cellular Gpx2 is predominantly regulated by $\operatorname{Trx} 1$ and $\operatorname{Trx} 2$ (cytoplasmic thioredoxin) [4]. Here, we focused on the redox regulation of mitochondrial Gpx2. The redox state of mitochondrial Gpx2 was determined by the AMS modification assay. As shown in Fig. 3, approximately half of the mitochondrial Gpx2 was in the oxidized form when mitochondria were isolated from wild-type 
cells without treatment with $\mathrm{H}_{2} \mathrm{O}_{2}$. Previously, we have reported that the bulk cellular Gpx2 was essentially in the reduced form in wild-type cells untreated with peroxides [4]. The occurrence of oxidized Gpx2 in mitochondria prepared from $\mathrm{H}_{2} \mathrm{O}_{2}$-untreated cells is presumably due to oxidation during the preparation. Nonetheless, the proportion of oxidized Gpx2 in mitochondria prepared from trx $1 \Delta \operatorname{tr} x 2 \Delta$ cells was higher than that of wild-type cells, which indicates that $\operatorname{Trx} 1$ and Trx2 have roles in the redox regulation of mitochondrial Gpx2 in cells untreated with $\mathrm{H}_{2} \mathrm{O}_{2}$. Furthermore, the proportion of oxidized $\mathrm{Gpx} 2$ in mitochondria was greatly increased when mitochondria were isolated from $\operatorname{tr} x 3 \Delta$ cells as well as $\operatorname{trx} 1 \Delta \operatorname{tr} x 2 \Delta$ cells treated with $\mathrm{H}_{2} \mathrm{O}_{2}$. Considering the localization of thioredoxin, i. e. Trx 1 and Trx 2 in the cytoplasm and Trx 3 in the mitochondrial matrix, $\operatorname{Trx} 1$ and $\operatorname{Tr} x 2$ may reduce Gpx2 associated with the outer membrane of mitochondria, while $\operatorname{Trx} 3$ may reduce that associated with the surface of the inner membrane of the matrix-side. It should be noted that the level of Gpx2 is high in trx $1 \Delta \operatorname{trx} 2 \Delta$ cells untreated with $\mathrm{H}_{2} \mathrm{O}_{2}$, because thioredoxin (Trx1 and $\operatorname{Trx} 2$ ) is a negative regulator of Yap1 [11], a transcriptional activator of $G P X 2[1,12]$; and therefore, Yap1 is constitutively activated in the $\operatorname{trx} 1 \Delta \operatorname{tr} x 2 \Delta$ mutant, thereby enhancing $G P X 2$ expression.

\subsection{Effects of GPX2's disruption on sporulation}

Comprehensive analyses of the physical interactions of yeast proteins have been conducted using different analytical methods. It has been reported that Gpx2 physically interacts with several proteins. Since we have demonstrated that Gpx2 is distributed in mitochondria, we focused on Fmp45, a mitochondrial membrane-integral protein. Tarassov et al. [13] revealed the physical interaction between Gpx2 and Fmp45 in vivo with a protein-fragment complementation 
assay. It has been reported that a deficiency in Fmp45 reduces sporulation efficiency [14]. We confirmed that the sporulation efficiency of $f m p 45 \Delta / f m p 45 \Delta$ diploid cells was reduced (Fig. 4). So, we determined the effect of the loss of Gpx2 on the sporulation efficiency of diploid cells. As shown in Fig. 4, the sporulation efficiency of $g p x 2 \Delta / g p x 2 \Delta$ cells was decreased compared with that of $G P X 2 / G P X 2$ cells, whose rate was comparable to that of $f m p 45 \Delta / f m p 45 \Delta$ cells. Next, we determined whether any correlation between Gpx2 and Fmp45 exists in terms of the reduction in sporulation efficiency. The sporulation efficiency of the fmp $45 \Delta g p x 2 \Delta / f m p 45 \Delta g p x 2 \Delta$ mutant did not decrease further compared with that of the

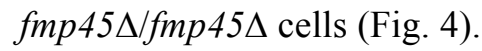

\section{Discussion}

The cellular localization of a protein provides a powerful hint as to its function. Previously, we have tried to determine the subcellular distrubution of Gpx2 using a GFP-tagged Gpx2, and found that the fluorescence derived from Gpx2-GFP was observed as punctate foci scattered within the cell (Tsuzi, D., Maeta, K., Izawa, S., and Inoue, Y., unpublished results); however, direct evidence that Gpx2 exists in distinctive organelles has not been obtained. Additionally, since the gpx $2 \Delta$ mutant did not exhibit obvious phenotypes, it is difficult to verify whether GFP-tagged Gpx2 is correctly distributed in the cell and functioning properly through complementation of the mutant's phenotype. Here, we adopted biochemical approaches to determine the localization of Gpx2.

We have demonstrated that Gpx2 is present in both the cytoplasm and mitochondria. The mitochondrial Gpx2 shows a characteristic distribution, i. e. some is associated with the 
surface of the outer membrane on the cytoplasmic-side, while the rest is associated with the surface of the inner membrane on the matrix-side. Considering the results of biochemical analyses, Gpx2 seems to be recruited to the mitochondrial outer membrane through ionic interaction (Fig. 2B). The pI value of Gpx2 is calculated to be 8.8 based on its amino acid sequence, therefore, Gpx2 is likely to be positively charged at a physiological $\mathrm{pH}$, which may enable this protein to associate with the mitochondrial membranes that are negatively charged due to phosphorus groups of phospholipids. We found that Gpx2 carrying an HA-tag at the C terminus, which has a lower pI (5.5) value, was not properly localized to mitochondria (Supplemental Fig. S1). Since Gpx2-HA is supposed to be negatively charged at a physiological $\mathrm{pH}$, the ionic interaction with the mitochondrial membrane might have been inhibited. Hence, the positive charge of Gpx2 might be one of the factors that enable this protein to attach to the mitochondrial outer membrane. In addition, Gpx2 does not have the predicted signal sequence at the $\mathrm{N}$ terminus for translocation into mitochondria. Indeed, the apparent molecular weight of the mitochondrial Gpx2 was the same as that of the cytoplasmic protein. In addition, the Gpx2 protein carrying a FLAG-tag at the $\mathrm{N}$ terminus was properly translocated to mitochondria with Western blotting using anti-FLAG antibody (Supplemental Fig. S1), and therefore, the processing of the $\mathrm{N}$ terminus is not likely to occur during the translocation of Gpx2 into mitochondria. Hence, the mechanism by which Gpx2 is translocated into the mitochondrial matrix is of considerable interest.

Avery and Avery [15] have reported that Gpx2 is active toward phospholipid hydroperoxide in vitro. Among mammalian GPxs, only PHGPx/GPx4 (phospholipid hydroperoxide GPx) is able to attack glycerophosphate hydroperoxides, and Gpx2 is the 
orthologue of PHGPx/GPx4 [4]. Therefore, it is feasible that Gpx2 protects the integrity of the mitochondrial membrane by preventing the peroxidation of phospholipids. On the other hand, Entian et al. [16] have reported that gpx2 2 cells have round-shaped mitochondria as observed under an electron microscope. These authors named the GPX2 gene AMI1 for " $\underline{a}$ berrant mitochondria". In logarithmically growing yeast cells, mitochondria show a tubular form with a branched network along the cell cortex [for a review, see Ref. 17]. In our preliminary experiments using the mitochondrial matrix-targeting GFP (mt-GFP) [18], the proportion of cells possessing the mitochondria in the network structure seemed somehow lower among gpx2 2 cells than wild-type cells (Supplemental Fig. S2). Considering the localization of Gpx2 (i.e. the surface of the outer membrane of mitochondria), the loss of Gpx2 might influence the function of the factor(s) involved in the fusion of mitochondria, such as Fzo1-Mgm1-Ugo1 complex [19-21]. In addition, if Gpx2 functions as an antioxidant to reduce phospholipid hydroperoxides in the mitochondrial membrane, its loss may reduce the integrity of the mitochondrial membrane to decrease the efficiency of mitochondrial membrane docking. However, since it is difficult to quantitate the change of mitochondrial morphology, we need to define an index to evaluate the morphological change of mitochondria.

In addition to the cellular localization of proteins, the physical and/or genetic interaction among gene products whose the functions are known would provide a clue as to the related physiological role of a function-unknown partner. Fmp45 is a mitochondrial membrane-integral protein, and involved in the process of sporulation. It has been reported that Fmp45 physically interacts with Gpx2 [13]. Considering that Gpx2 is associated with the mitochondrial membrane, it is feasible that these proteins share some functions in mitochondria. 
It has been well established that unimpaired mitochondrial function is necessary for sporulation [22]. Here we have demonstrated that diploid cells defective in GPX2 show reduced efficiency in sporulation. Additionally, the simultaneous disruption of FMP45 and GPX2 did not have an additive effect in terms of the reduction of sporulation efficiency as compared with

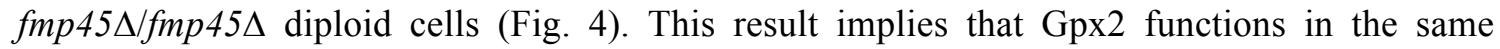
regulatory pathway of sporulation as Fmp45, which seems to support the notion of physical interaction between Fmp45 and Gpx2. Further study is now underway to figure out the function of mitochondrial Gpx2 in the process of sporulation.

\section{Acknowledgements}

We thank Dr. T. Endo for antibodies for Tom70, Tim50, and Hsp60, and Dr. W. Neupert for mt-GFP plasmids. We are also grateful to Dr. F. Ling for technical advice on the preparation of mitochondria, and evaluation of the morphological change in mitochondria.

\section{References}

[1] Y. Inoue, T. Matsuda, S. Izawa, A. Kimura, Genetic analysis of glutathione peroxidase in oxidative stress response of Saccharomyces cerevisiae. J. Biol. Chem. 274 (1999) 27002-27009.

[2] B. Hofmann, H.J. Hecht, L. Flohé, Peroxiredoxins, Biol. Chem. 383 (2002) 347-364.

[3] T. Ohdate, K. Kita, Y. Inoue, Kinetics and redox regulation of Gpx1, an atypical 2-Cys peroxiredoxin, in Saccharomyces cerevisiae, FEMS Yeast Res. 10 (2010) 787-790.

[4] T. Tanaka, S. Izawa, Y. Inoue, GPX2, encoding a phospholipid hydroperoxide glutathione peroxidase homologue, codes for an atypical 2-Cys peroxiredoxin in Saccharomyces cerevisiae, J. Biol. Chem. 280 (2005) 42078-42087.

[5] A. Delaunay, D. Pflieger, M.B. Barrault, J. Vinh, M.B. Toledano, A thiol peroxidase is an 
$\mathrm{H}_{2} \mathrm{O}_{2}$ receptor and redox-transducer in gene activation, Cell 111 (2002) 471-481.

[6] U. Güldener, J. Heinisch, G.J. Köhler, D. Voss, J.H. Hegemann, A second set of loxP marker cassettes for Cre-mediated multiple gene knockouts in budding yeast, Nucleic Acids Res. 30 (2002) e23.

[7] M. Naoe, Y. Ohwa, D. Ishikawa, C. Ohshima, S. Nishikawa, H. Yamamoto, T. Endo, Identification of Tim40 that mediates protein sorting to the mitochondrial intermembrane space, J. Biol. Chem. 279 (2004) 47815-47821.

[8] C. Meisinger, T. Sommer, N. Pfanner, Purification of Saccharomcyes cerevisiae mitochondria devoid of microsomal and cytosolic contaminations, Anal. Biochem. 287 (2000) 339-342.

[9] H. Yamamoto, M. Esaki, T. Kanamori, Y. Tamura, S. Nishikawa, T. Endo, Tim50 is a subunit of the TIM23 complex that links protein translocation across the outer and inner mitochondrial membranes, Cell 111 (2002) 519-528.

[10] Y. Tamura, Y. Harada, K. Yamano, K. Watanabe, D. Ishikawa, C. Ohshima, S. Nishikawa, H. Yamamoto, T. Endo, Identification of Tam41 maintaining integrity of the TIM23 protein translocator complex in mitochondria, J. Cell Biol. 174 (2006) 631-637.

[11] S. Izawa, K. Maeda, K. Sugiyama, J. Mano, Y. Inoue, A. Kimura, Thioredoxin deficiency causes the constitutive activation of Yap1, an AP-1-like transcription factor in Saccharomyces cerevisiae, J. Biol. Chem. 274 (1999) 28459-28465.

[12] D. Tsuzi, K. Maeta, Y. Takatsume, S. Izawa, Y. Inoue, Regulation of the yeast phospholipid hydroperoxide glutathione peroxidase $G P X 2$ by oxidative stress is mediated by Yap1 and Skn7, FEBS Lett. 565 (2004) 148-154.

[13] K. Tarassov, V. Messier, C.R. Landry, S. Radinovic, M.M. Serna Molina, I. Shames, Y. Malitskaya, J. Vogel, H. Bussey, S.W. Michnick, An in vivo map of the yeast protein interactome, Science 320 (2008) 1465-1470.

[14] M.E. Young, T.S. Karpova, B. Brugger, D.M. Moschenross, G.K. Wang, R. Schneiter, F.T. Wieland, J.A. Cooper, The Sur7p family defines novel cortical domains in Saccharomyces cerevisiae, affects sphingolipid metabolism, and is involved in sporulation, Mol. Cell. Biol. $22(2002) 927-934$.

[15] A.M. Avery, S.V. Avery, Saccharomyces cerevisiae expresses three phospholipids hydroperoxide glutathione peroxidases, J. Biol. Chem. 276 (2010) 33730-33735.

[16] K.D. Entian, T. Schuster, J.H. Hegemann, D. Becher, H. Feldmann, U. Guldener, R. Gotz, M. Hansen, C.P. Hollenberg, G. Jansen, W. Kramer, S. Klein, P. Kotter, J. Kricke, H. 
Launhardt, G. Mannhaupt, A. Maierl, P. Meyer, W. Mewes, T. Munder, R.K. Niedenthal, R.M. Ramezani, A. Rohmer, A. Romer, M. Rose, B. Schafer, M.L. Siegler, J. Vetter, N. Wilhelm, K. Wolf, F.K. Zimmermann, A. Zollner, A. Hinnen, Functional analysis of 150 deletion mutants in Saccharomyces cerevisiae by a systematic approach, Mol. Gen. Genet. 262 (1999) 683-702.

[17] K. Okamoto, J.M. Shaw, Mitochondrial morphology and dynamics in yeast and multicellular eukaryote, Annu. Rev. Genet. 39 (2005) 503-536.

[18] B. Westermann, W. Neupert, Mitochondria-targeted green fluorescent proteins: convenient tools for the study of organelle biogenesis in Saccharomyces cerevisiae, Yeast 16 (2000) 1421-1427.

[19] E.D. Wong, J.A. Wagner, S.V. Scott, V. Okreglak, T.J. Holewinske, A. Cassidy-Stone, J. Nunnari, The intramitochondrial dynamin-related GTPase, Mgm1p, is a component of a protein complex that mediates mitochondrial fusion, J. Cell Biol. 160 (2003) 303-311.

[20] H. Sesaki, R.E. Jensen, Ugolp links the Fzolp and Mgm1p GTPases for mitochondrial fusion. J. Biol. Chem. 279 (2004) 28298-28303.

[21] H. Sesaki, S.M. Southard, M.P. Yaffe, R.E. Jensen, Mgm1p, a dynamin-related GTPase, is essential for fusion of the mitochondrial outer membrane, Mol. Biol. Cell 14 (2003) 2342-2356.

[22] A.M. Neiman, Ascospore formation in the yeast Saccharomyces cerevisiae, Microbiol. Mol. Biol. Rev. 69 (2005) 565-584. 


\section{Figure legends}

Fig. 1. Subcellular localization of Gpx2

(A) The distribution of proteins in each fraction was analyzed by Western blotting. S13 (supernatants) and P13 (crude mitochondria) were separated by the centrifugation of homogenates at $13000 \mathrm{x} g$ for $10 \mathrm{~min}$. S100 (supernatants) and P100 (pellets) were separated by the centrifugation of S13 fractions at $100000 \times \mathrm{g}$ for $20 \mathrm{~min}$. Por1, Dpm1, and Pgk1 are the marker proteins for mitochondria (mito), endoplasmic reticulum (ER), and cytoplasm (cyt), respectively. (B) P13 fractions were subjected to the ultracentrifugation of a three-step sucrose density gradient at $134000 \times \mathrm{g}$ for $1 \mathrm{~h}$ at $2^{\circ} \mathrm{C}$.

Fig. 2. Determination of mitochondrial localization of Gpx2

(A) Whole mitochondria, mitoplasts, and solubilized mitoplasts were treated with various concentrations of PK as indicated in the figure for $30 \mathrm{~min}$ on ice. $\mathrm{OM}$ and $\mathrm{IM}$ represent the outer membrane and inner membrane of mitochondria, respectively. (B) The mitochondria and mitoplasts were treated as follows: mitochondria were treated with $0.5 \mathrm{M} \mathrm{NaCl}$ or $0.1 \mathrm{M}$ $\mathrm{Na}_{2} \mathrm{CO}_{3}$ for $60 \mathrm{~min}$ on ice, while mitoplasts were treated with sonication $(50 \mathrm{~W}, 15 \mathrm{sec}, 3 \mathrm{sets})$. After centrifugation of each sample at $100000 \times \mathrm{g}$ for $30 \mathrm{~min}$ at $4^{\circ} \mathrm{C}$, pellets $(\mathrm{Ppt})$ and supernatants (Sup) were subjected to SDS-PAGE followed by Western blotting. OM and IM represent the outer membrane and inner membrane of mitochondria, respectively.

Fig. 3. Redox regulation of mitochondrial Gpx2 
Cells (WT, trx $1 \Delta \operatorname{tr} x 2 \Delta$, and $\operatorname{tr} x 3 \Delta$ ) were cultured in SD medium to a log phase of growth, and treated with or without $0.4 \mathrm{mM} \mathrm{H}_{2} \mathrm{O}_{2}$ for $1 \mathrm{~h}$. After the isolation of mitochondria, the mitochondrial Gpx2 was modified with AMS. Proteins were separated by non-reducing SDS-PAGE.

Fig. 4. Effects of the loss of Gpx2 on sporulation

Diploid cells $(G P X 2 / G P X 2, g p x 2 \Delta / g p x 2 \Delta, f m p 45 \Delta / f m p 45 \Delta$, and gpx2 2 fmp $45 \Delta / g p x 2 \Delta f m p 45 \Delta)$ were incubated on sporulation medium agar plates at $25^{\circ} \mathrm{C}$. Approximately 1000 cells were counted each day, and the proportion of sporulated cells (asci with four spores) versus total cells counted is shown. Values represent the average for three independent experiments \pm standard deviation. 
Fig. 1

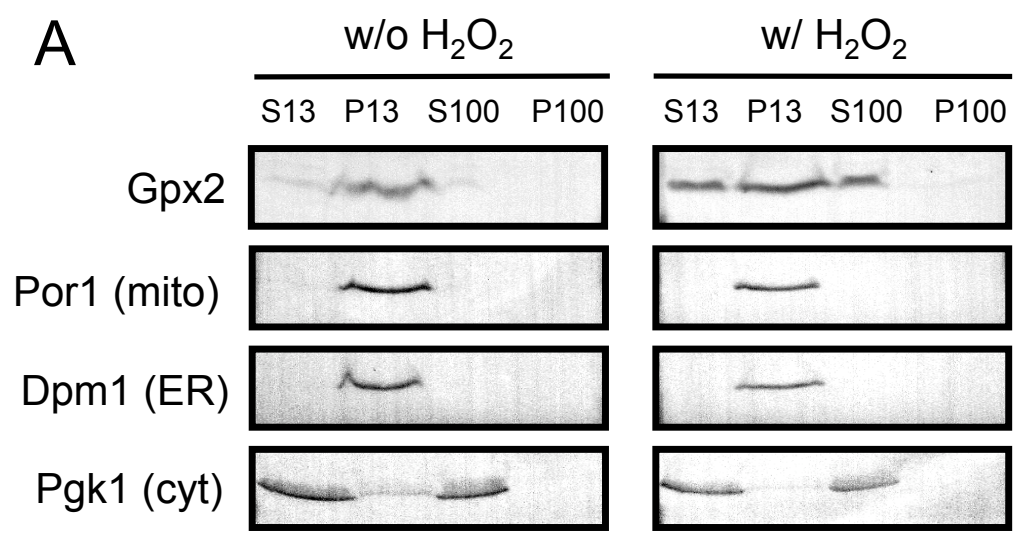

B Fraction No

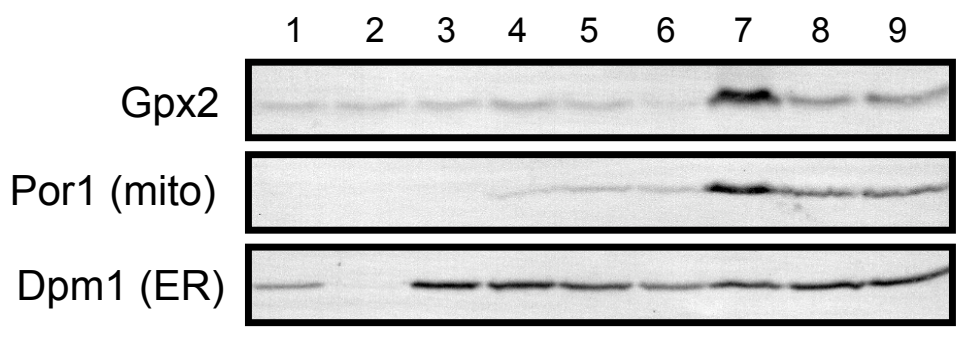


Fig. 2
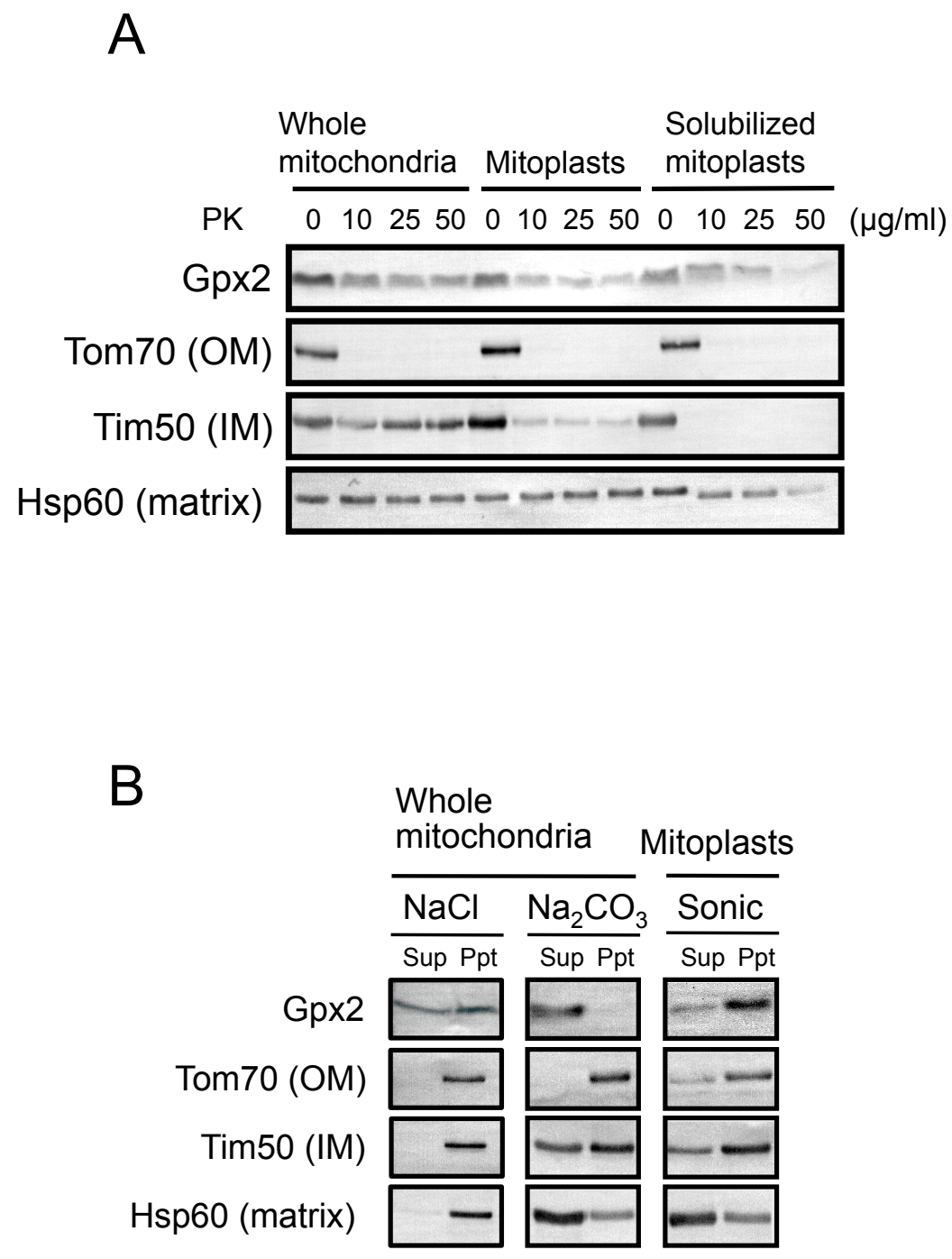
Fig. 3

$$
\begin{aligned}
& \frac{\text { w/o } \mathrm{H}_{2} \mathrm{O}_{2}}{\text { WT } \operatorname{trx} 1 / 2 \Delta \operatorname{trx} 3 \Delta} \frac{\mathrm{w} / \mathrm{H}_{2} \mathrm{O}_{2}}{\text { WT } \operatorname{trx} 1 / 2 \Delta \operatorname{trx} 3 \Delta} \\
& \text { Gpx2 }
\end{aligned}
$$


Fig. 4

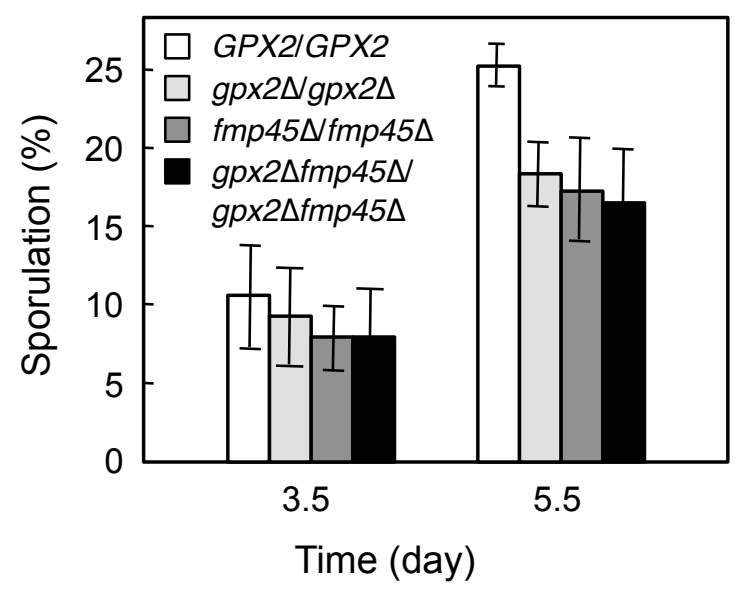




\section{SUPPLEMENTARY DATA}

\section{Supplemental Materials and methods}

\section{Subcellular fractionation}

The subcellular fractionation experiment was done essentially as described by Meisinger et al. [1] with slight modifications. Cells grown to a log phase of growth were treated with $4 \mathrm{mg} / \mathrm{ml}$ Zymolyase-100T (Seikagaku Kogyo Co.) in potassium phosphate buffer (pH 7.4) containing $1.2 \mathrm{M}$ sorbitol at $30^{\circ} \mathrm{C}$ for $60 \mathrm{~min}$ to obtain spheroplasts. After the homogenization of spheroplasts by 30 strokes in a Dounce glass homogenizer in $15 \mathrm{ml}$ of ice-cold homogenization buffer [0.6 M sorbitol, $10 \mathrm{mM}$ Tris- $\mathrm{HCl}(\mathrm{pH}$ 7.4), $1 \mathrm{mM}$ EDTA, and $1 \mathrm{mM}$ phenylmethyl sulfonyl fluoride (PMSF)], cell debris and nuclei were removed by centrifugation at $1500 \mathrm{x} g$ for $5 \mathrm{~min}$. The supernatants were centrifuged at $1800 \mathrm{x} g$ for $10 \mathrm{~min}$ twice, and the resultant supernatants were further centrifuged at $13000 \mathrm{x} g$ for $10 \mathrm{~min}$ to precipitate crude mitochondria. The crude mitochondrial pellets were washed with SEM buffer [250 mM sucrose, $1 \mathrm{mM}$ EDTA, and $10 \mathrm{mM}$ MOPS (pH 7.2)], and again centrifuged at $13000 \mathrm{xg}$ for $10 \mathrm{~min}$. The resulting crude mitochondrial fractions (P13) were then resuspended in SEM buffer to give a final concentration of $1 \mathrm{mg}$ of protein per $\mathrm{ml}$. To prepare the cytoplasmic fraction, the supernatants after the preparation of crude mitochondria (S13), were centrifuged at $100000 \times \mathrm{g}$ for $20 \mathrm{~min}$. The resultant supernatants were S100 fractions, and the resultant precipitates were P100 fractions. Each fraction was subjected to SDS-PAGE followed by Western blotting using respective antibodies to verify the localization of marker proteins.

To separate ER from the crude mitochondrial fractions, the crude mitochondria (250 $\mu \mathrm{g}$ protein) in $250 \mu \mathrm{l}$ of SEM buffer were loaded onto the top of a three-step sucrose density gradient $[0.75 \mathrm{ml} 60 \%, 2 \mathrm{ml} 32 \%, 0.75 \mathrm{ml} 23 \%, 0.75 \mathrm{ml} 15 \%(\mathrm{w} / \mathrm{v})$ sucrose in EM buffer (10 $\mathrm{mM}$ MOPS, $\mathrm{pH} 7.2$, and $1 \mathrm{mM}$ EDTA)]. The centrifugation was done at $134000 \mathrm{x} g$ for $1 \mathrm{~h}$ at $2^{\circ} \mathrm{C}$ with a RPS40-T rotor (himac CP75 $\beta$, Hitachi Koki). Each fraction $(500 \mu \mathrm{l})$ was collected from the top of the tube ( 9 fractions), and proteins were precipitated by adding $125 \mu 1$ of $100 \%$ trichloroacetic acid (TCA). The mixture was centrifuged at $13000 \mathrm{x} g$ for $10 \mathrm{~min}$ at $4^{\circ} \mathrm{C}$, and the precipitates were washed once with acetone. After removal of the acetone, the dried materials were suspended in $40 \mu \mathrm{l}$ of $1 \mathrm{M}$ Tris solution. The suspension was mixed with $10 \mu \mathrm{l}$ of $5 \mathrm{x}$ sample buffer, and the mixture was boiled for $5 \mathrm{~min}$. The sample was subjected to SDS-PAGE followed by Western blotting.

\section{Proteinase K treatment}

Treatment of mitochondria with proteinase $\mathrm{K}$ to determine the localization of proteins was done essentially as described by Yamamoto et al. [2] with slight modifications. Briefly, the crude mitochondria ( $200 \mu \mathrm{g}$ protein) were suspended in $200 \mu 1$ of TS buffer [0.6 M sorbitol, and $10 \mathrm{mM}$ Tris- $\mathrm{HCl}$ (pH 7.4)]. Mitoplasts were generated with osmotic swelling by suspending the crude mitochondria (200 $\mu$ g protein) in a 10 -fold volume of $10 \mathrm{mM}$ Tris- $\mathrm{HCl}$ ( $\mathrm{pH}$ 7.4) buffer for $20 \mathrm{~min}$ on ice. The mitoplasts were collected by centrifugation at $13000 \mathrm{x} g$ 
for $10 \mathrm{~min}$, and suspended in $200 \mu \mathrm{l}$ of TS buffer. Solubilized mitoplasts were generated from the mitoplasts ( $200 \mu \mathrm{g}$ protein) by treatment with $0.1 \%$ Triton-X100 in $200 \mu 1$ of TS buffer for $20 \mathrm{~min}$ on ice. Each suspension of crude mitochondria, mitoplasts, and solubilized mitoplasts was treated with $10-50 \mu \mathrm{g} / \mathrm{ml}$ of proteinase $\mathrm{K}$ (Wako) for $30 \mathrm{~min}$ on ice. The reaction was stopped by addition of $1 \mathrm{mM}$ PMSF for $5 \mathrm{~min}$ on ice, and $50 \mu 1$ of $100 \%$ TCA was added. The precipitates were washed once with acetone. After removal of the acetone, the dried materials were suspended with $32 \mu 1$ of $1 \mathrm{M}$ Tris solution. The suspension was mixed with $8 \mu 1$ of $5 \mathrm{x}$ sample buffer, and the mixture was boiled for $5 \mathrm{~min}$. The sample was subjected to reducing SDS-PAGE followed by Western blotting.

\section{$\mathrm{NaCl}$, sonication, and $\mathrm{Na}_{2} \mathrm{CO}_{3}$ treatment}

Treatment of mitochondria with $\mathrm{NaCl}$, sonication, and $\mathrm{Na}_{2} \mathrm{CO}_{3}$ to determine the localization of proteins was done essentially as described by Yamamoto et al. [2] with slight modifications. Briefly, the crude mitochondria (200 $\mu$ g protein) were treated in $200 \mu 1$ of $0.5 \mathrm{M}$ $\mathrm{NaCl}$ or $0.1 \mathrm{M} \mathrm{Na}_{2} \mathrm{CO}_{3}$ in TS buffer containing $1 \mathrm{mM}$ PMSF for $30 \mathrm{~min}$ on ice. Mitoplasts (2 $\mathrm{mg}$ of protein) prepared by hypo-osmotic swelling as described previously were treated with sonication ( $50 \mathrm{~W}, 15 \mathrm{sec}, 3 \mathrm{sets})$ in $2 \mathrm{ml}$ of TS buffer. Each solution was centrifuged at 100000 $\mathrm{x} g$ for $30 \mathrm{~min}$ at $4^{\circ} \mathrm{C}$. The precipitates were suspended in $32 \mu 1$ of $1 \mathrm{M}$ Tris solution, and the suspension was mixed with $8 \mu \mathrm{l}$ of $5 \mathrm{x}$ sample buffer. The supernatants were mixed in $50 \mu \mathrm{l}$ of $100 \% \mathrm{TCA}$, the mixture was centrifuged at $13000 \mathrm{x} \mathrm{g}$ for $10 \mathrm{~min}$ at $4^{\circ} \mathrm{C}$, and the precipitates were washed once with acetone. After removal of the acetone, the dried materials were suspended with $32 \mu 1$ of $1 \mathrm{M}$ Tris solution. The suspension was mixed with $8 \mu 1$ of $5 \mathrm{x}$ sample buffer, and the mixtures were boiled for $5 \mathrm{~min}$. The sample was subjected to SDS-PAGE followed by Western blotting.

\section{References}

[1] C. Meisinger, T. Sommer, N. Pfanner, Purification of Saccharomcyes cerevisiae mitochondria devoid of microsomal and cytosolic contaminations, Anal. Biochem. 287 (2000) 339-342.

[2] H. Yamamoto, M. Esaki, T. Kanamori, Y. Tamura, S. Nishikawa, T. Endo, Tim50 is a subunit of the TIM23 complex that links protein translocation across the outer and inner mitochondrial membranes, Cell 111 (2002) 519-528. 


\section{Supplemental Table 1}

Yeast strains used in this study

\begin{tabular}{|c|c|}
\hline Strain & Relavant genotype \\
\hline YPH250 & 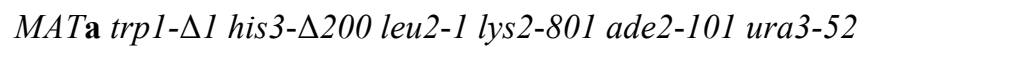 \\
\hline YPH252 & 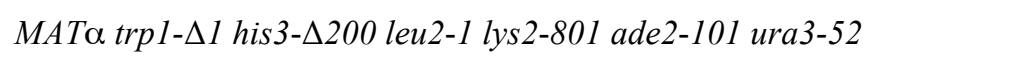 \\
\hline YPH274 & MATa/MATa YPH250 x YPH252 \\
\hline gpx $2 \Delta$ & YPH250, gpx2A::TRP1 \\
\hline $\operatorname{gpx} 2 \Delta$ & YPH252, gpx $2 \Delta:: h i s 5^{+}$ \\
\hline $\operatorname{tr} x 1 \Delta \operatorname{tr} x 2 \Delta$ & YPH250, $\operatorname{trx} 1 \Delta:: U R A 3 \operatorname{tr} x 2 \Delta:: H I S 3$ \\
\hline $\operatorname{tr} x 3 \Delta$ & YPH250, $\operatorname{tr} x 3 \Delta:: T R P 1$ \\
\hline$G P X 2 / G P X 2$ & same as $\mathrm{YPH} 274$ \\
\hline$g p x 2 \Delta / g p x 2 \Delta$ & 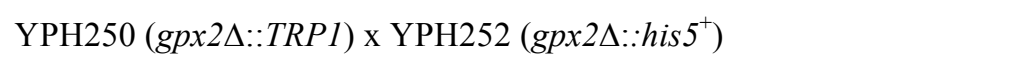 \\
\hline$f m p 45 \Delta / f m p 45 \Delta$ & YPH250 (fmp45 \\
\hline gpx $2 \Delta f m p 45 \Delta / g p x 2 \Delta f m p 45 \Delta$ & 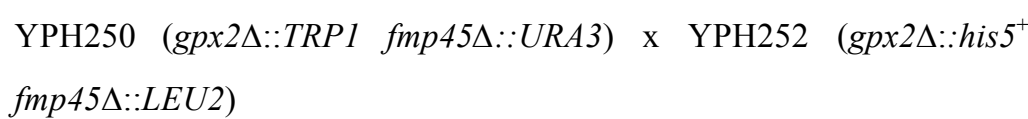 \\
\hline
\end{tabular}




\section{Legends for Supplemental Figures}

Supplemental Fig. S1. Localization of epitope-tagged Gpx2

Cells carrying plasmids for the HA-tagged GPX2 at the C terminus or FLAG-tagged GPX2 at the $\mathrm{N}$ terminus were cultured in SD medium until a log phase of growth, and mitochondria were prepared by sucrose density ultracentrifugation. Gpx2-HA and FLAG-Gpx2 were detected by anti-HA monoclonal antibody and anti-FLAG monoclonal antibody, respectively. Por1 and Dpm1 are the marker proteins for mitochondria (mito) and endoplasmic reticulum (ER), respectively.

Supplemental Fig. S2. Effects of the loss of Gpx2 on mitochondrial morphology Cells (wild type and gpx2A) carrying mitochondrial matrix-targeting GFP (mt-GFP) were cultured in SD medium to a log phase of growth, and the morphology of mitochondria was observed with fluorescence microscopy. 
Supplemental Fig. S1
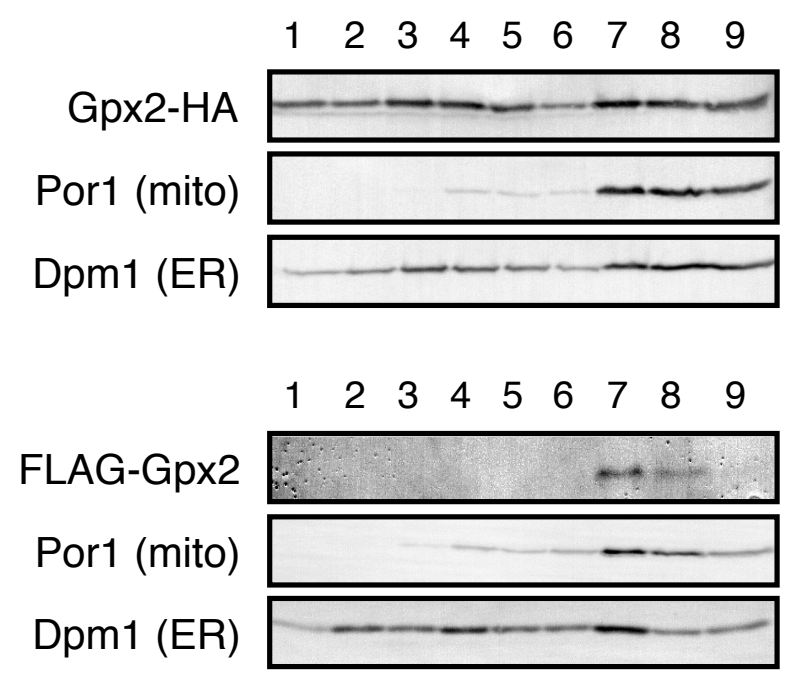
Supplemental Fig. S2
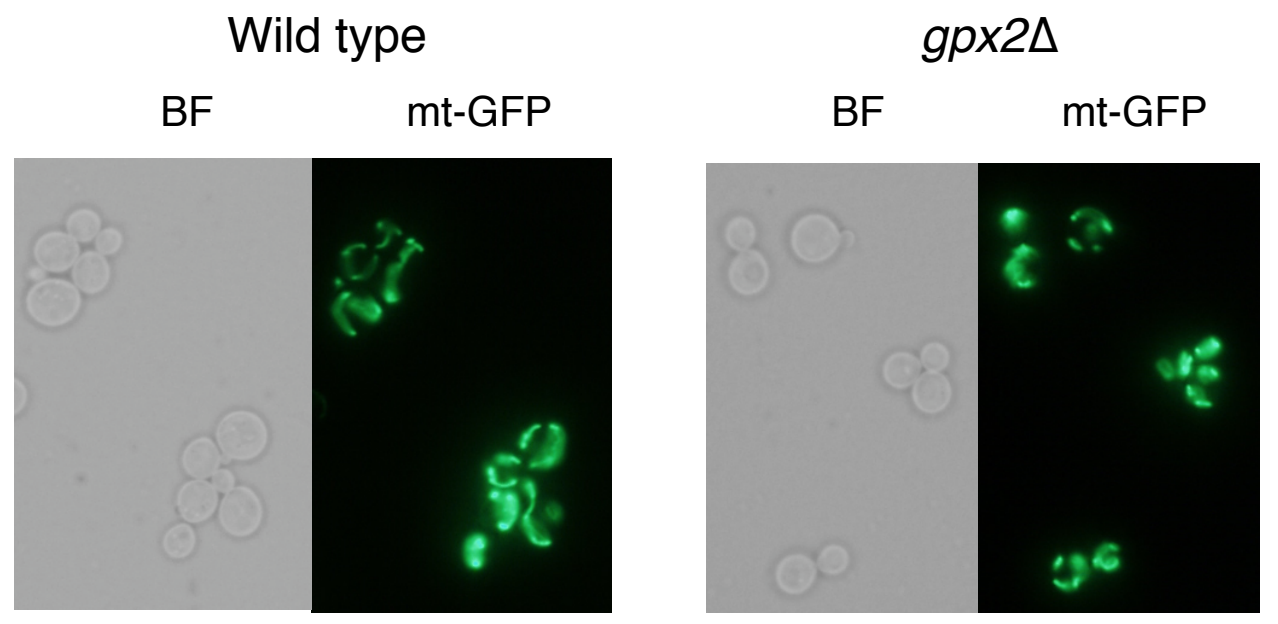